\title{
CHARACTERIZATION OF AIRBORNE PARTICLES IN MECHANICAL TEXTILE YARNS PROCESSING
}

\author{
DOI: $10.35530 /$ TT.2021.58
}

\author{
E. Visileanu*, C. Mihai, A. Ene, M.C. Grosu, R. Scarlat, A. Vladu \\ National Research Development Institute for Textile and Leather, Romania \\ (E-mail: e.visileanu@incdtp.ro)
}

\begin{abstract}
Nano and micro plastics (NP/MPs) represent one of the most challenging classes of micropollutants, with occurrence across all ecosystems and size distributions ranging from the nanometre to the millimetre scale. Natural environments are receiving MPs in the form of anthropogenic direct release as well as disintegrated and loose products of larger plastics via biological activities, mechanical abrasion, and UV radiation. During the processing steps, the textile yarns are subjected to friction either by different driving organs or between themselves at the binding points. The magnitude of the friction forces is influenced by the nature of the yarns, the structure of the yarn, the type, and the raw material from which the driving organs of the machines are made. The paper presents the shape and dimensions of the particle that is released in the air during the abrasion resistance test of three types of polyester yarns: spun yarn, multifilament yarn, and monofilament yarn. The structure composition of the particles consists of more microfibrils (34\%.) in the case of spun yarn and the finest microparticles were obtain from monofilament yarn $(0,004 \mu \mathrm{m})$.
\end{abstract}

Keywords: health, particles, fibres, stiffness, abrasion

\section{INTRODUCTION}

Plastics are highly versatile materials that have brought huge societal benefits. They can be manufactured at low cost and their lightweight and adaptable nature has a myriad of applications in all aspects of everyday life, including food packaging, consumer products, medical devices, and construction. By 2050, however, it is anticipated that an extra 33 billion tonnes of plastic will be added to the planet. Given that most currently used plastic polymers are highly resistant to degradation, this influx of persistent, complex materials is a risk to human and environmental health. Continuous daily interaction with plastic items allows oral, dermal, and inhalation exposure to chemical components, leading to the widespread presence in the human body of chemicals associated with plastics [1-3].

Nano and micro plastics (NP/MPs) represent one of the most challenging classes of micro-pollutants, with occurrence across all ecosystems and size distributions ranging from the nanometre to the millimetre scale. These broad composition and size distribution ranges limit the efficiency of detection methods, often inherently focused on a single and narrow class of NP/MPs sizes. In addition to their demonstrated native toxicity, NP/MPs may act as efficient carriers of pollutants and pathogens onto their surface, facilitating the transfer and penetration of other classes of hazardous materials [4-6].

The mismanagement and dumping of domestic and commercial plastic wastes are the major cause of pollution in a natural setting. Natural environments are receiving MPs in the form of anthropogenic direct release as well as disintegrated and loose products of larger 
plastics via biological activities, mechanical abrasion, and UV radiation. NPs, imposed more potential risk in comparison to MPs as they can easily able to enter cells/ tissues. Complexity in separation and identification of NPs, their abundance in the environmental setting has been generally overlooked to date. Hence, the physical presence and health menace of NPs may be underrated [7-8].

\section{MATERIALS AND METHODS}

Textile fabric may be defined as the flexible assembly of fibres or yarns, either natural or manmade. It may be produced by several techniques, the most common of which are weaving, knitting, bonding, felting, or tufting. Conventional fabrics (woven, knitted) are produced in such a way that the fibres are first converted into yarn and subsequently this yarn is converted into fabric [9]. During the processing steps, the yarns are subjected to friction either by different driving organs or between themselves at the binding points. The magnitude of the friction forces is influenced by the nature of the yarns, the structure of the yarn, the type, and the raw material from which the driving organs of the machines are made.

Due to the friction forces, bending, stretching of the yarns, that take place during these processes, degradations of fibres/yarns occur and micro plastics/microfibres are released into the air/water. A series of laboratory devices simulate these actions to determine the strength of yarns or semi-finished products to the action of frictional forces.

Fibre fragments are one of the dominant types of micro plastics in environmental samples, suggesting that synthetic textiles are a potential source of microplastics for the environment. Textile abrasion can induce fibre fibrillation and therefore lead to the formation of much finer fibre fragments. To determine the abrasion resistance of the yarns, a testing device was built (figure 1), whose constructive principle consists in simulating the friction phenomena, which the textile yarns are subjected to, during the steps of textile mechanical processing (spinning, warping, weaving knitting) and electronic monitoring of their behaviour.
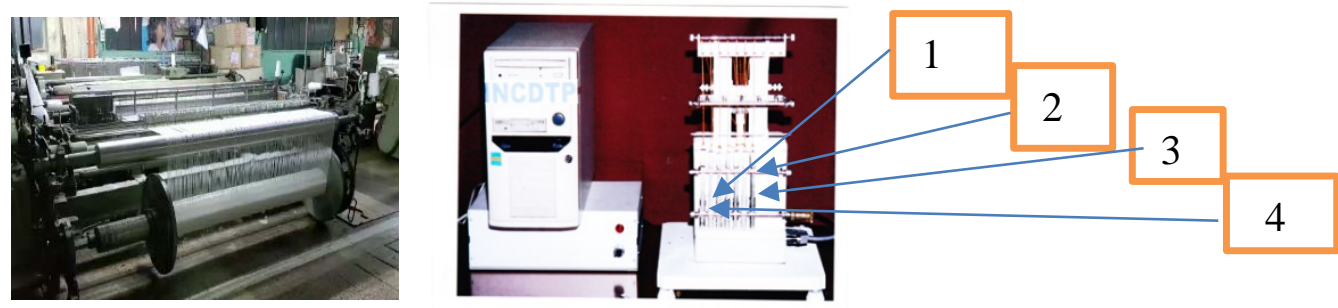

Figure 1. Weaving machine and yarn rubbing device: 1 - tensioning mechanism; 2 - friction mechanism; 3 - the drive mechanism; 4 - the weaving simulation mechanism

The device consists of the following components: 1 - tensioning mechanism, 2 friction mechanism, 3 - the drive mechanism, 4 - the weaving simulation mechanism. The device simultaneously performs the friction of 10 yarns in the cockles, their movement, with a stroke length of $0-40 \mathrm{~mm}$ is generated by a motor whose speed can be varied. The preliminary pretension load of the yarns can be modified in increments of $10 \mathrm{~g}$, within the limits: 50-140 mg.

The method for determining the abrasion resistance of textile yarns is in accordance with the international standards ISO 9290 and ASTM-D 1422. To collect the particles released during the rubbing of the cochlear yarns, the device was covered with a box with 
antistatic walls. The collection of particles was done by the static method (deposition) in Petri dishes, sterile in the flow, with ventilation, with a diameter of $90 \mathrm{~mm}$.

\section{RESULTS AND DISCUSSION}

For the laboratory experiments, 3 variants of $100 \%$ PES yarns with the different structures were used: Nm 20/2 spun yarn (FPES), 195/32f dtex multifilament yarn (MPES), and $0.19 \mathrm{~mm}$ monofilament yarn (MOPES) of whose characteristics are presented in table 1 and in figures 3, 4, 5 and 6 are their diagrams by comparison.

Table 1. Type sizes for camera-ready papers

\begin{tabular}{|c|c|c|c|c|c|}
\hline & & & \begin{tabular}{|c|} 
Spun yarn \\
$100 \%$ PES-FPES
\end{tabular} & $\begin{array}{l}\text { Multifilament yarn } \\
100 \% \text { PES - MPES }\end{array}$ & \begin{tabular}{|l} 
Monofilament yarn \\
$100 \%$ PES-MOPES
\end{tabular} \\
\hline No. & Yarn feature / variant & UM & & & \\
\hline \multirow{5}{*}{1} & \multirow{2}{*}{ Length density } & Tex/Nm & $50.6 \times 2 / 19.8 / 2$ & - & - \\
\hline & & Den/dtex & - & 175.5/32f/195.0/32f & $342 / 380$ \\
\hline & Coefficient of variation & $\%$ & 4.9 & 1.34 & - \\
\hline & Standard deviation & - & 4.96 & 0.26 & - \\
\hline & Diameter & $\mathrm{mm}$ & 0.22 & 0.14 & 0.190 \\
\hline \multirow{3}{*}{2} & Breaking strength & $\mathrm{N}$ & 35.51 & 6.25 & 16.7 \\
\hline & Coefficient of variation & $\%$ & 4.2 & 8.61 & 2.9 \\
\hline & Standard deviation & - & 1.5 & 0.53 & 0.45 \\
\hline \multirow{3}{*}{3} & Elongation at break & $\%$ & 16.23 & 32.08 & 28.35 \\
\hline & Coefficient of variation & $\%$ & 2.84 & 8.83 & 7.9 \\
\hline & Standard deviation & & 0.46 & 2.83 & 2.2 \\
\hline \multirow{3}{*}{4} & Torsion/twist & $\mathrm{t} / \mathrm{m}$ & $469.0 / 321.2$ & 39.6 & - \\
\hline & Coefficient of variation & $\%$ & $3.57 / 3.67$ & 11.61 & - \\
\hline & Standard deviation & - & $8.38 / 2.93$ & 2.3 & - \\
\hline \multirow{3}{*}{5} & Deformation resistance & $\mathrm{KPa}$ & 147.7 & 119.0 & 114.1 \\
\hline & Coefficient of variation & $\%$ & 6.89 & 1.62 & 3.67 \\
\hline & Standard deviation & - & 10.13 & 1.93 & 4.19 \\
\hline \multirow{3}{*}{6} & Deformation & $\mathrm{mm}$ & 14.4 & 14.2 & 9.5 \\
\hline & Coefficient of variation & $\%$ & 22.8 & 4.93 & 11.75 \\
\hline & Standard deviation & - & 3.29 & 0.70 & 1.12 \\
\hline 7 & Young's modulus & $\mathrm{MPa}$ & 7142.8 & 1660.6 & 5357.0 \\
\hline
\end{tabular}

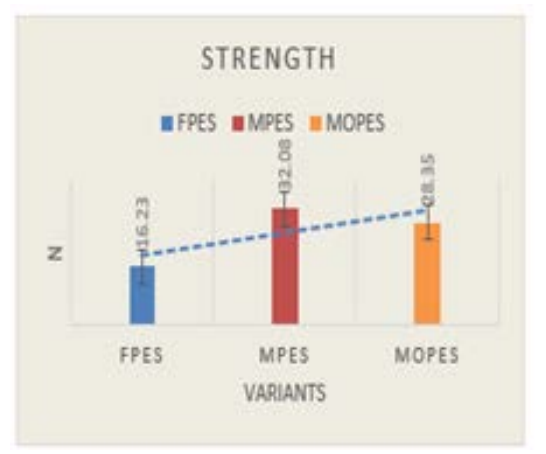

Figure 3. Breaking resistance

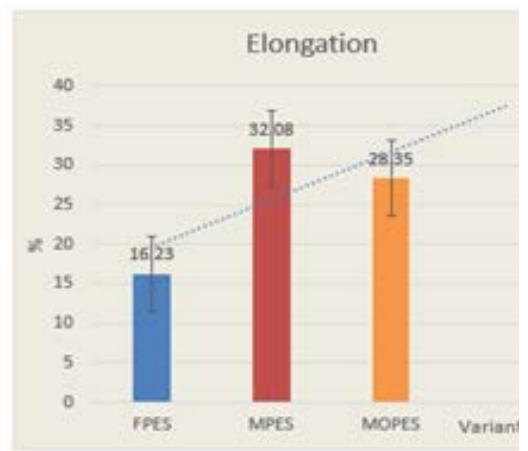

Figure 4. Elongation 


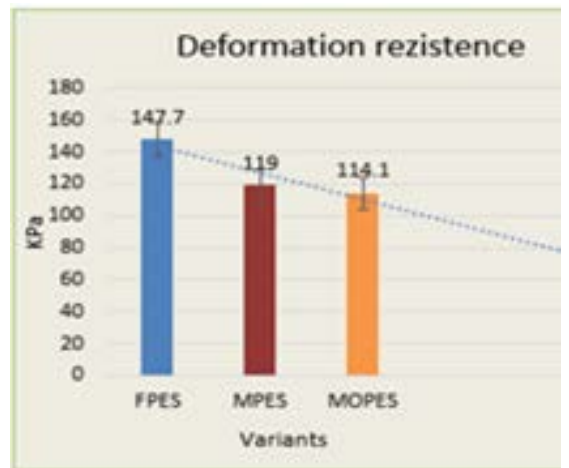

Figure 5. Deformation resistance

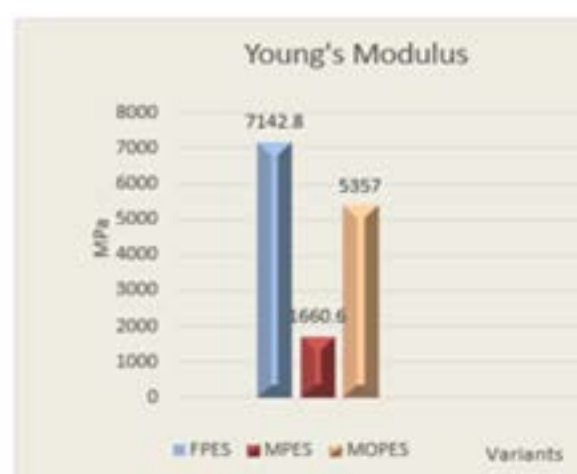

Figure 6. Young's modulus

The deformation resistance of the yarns was determined on the Tru Burst3 Bursting Strength Tester having upper-pressure limit - $100 \mathrm{kPa}$ and distension range between: 0.1-70 $\mathrm{mm}$ and the method applied according to SR EN ISO13937-4 / 2003 (adapted). The highest breaking strength $(\mathrm{N})$ is obtained for the FPES variant $(35.51 \mathrm{~N})$ which records the highest values of deformation resistance of $147.7 \mathrm{KPa}$, deformation $(14.4 \mathrm{~mm})$, and modulus of elasticity (7142.8 MPa), but with the lowest value of elongation at break (16.23\%).

The same correlation between the breaking strength and young's modulus is also maintained in the case of the MOPES variant (16.7 $\mathrm{N}$ and respectively $5357.0 \mathrm{KPa}$ ) and MPES (6.25N and respectively $1660.6 \mathrm{KPa}$. The highest resistance to deformation is obtained for the FPES variant (147.7 KPa), followed by MPES (119.0 KPa) and MOPES $(114.1 \mathrm{KPa})$. The deformation variation $(\mathrm{mm})$ follows the same order: FPES $(14.4 \mathrm{~mm})$, MPES $(14.2 \mathrm{~mm})$ and MOPES $(9.5 \mathrm{~mm})$. The laboratory experiments of collecting the particles released in the air during the frictional stress of the three yarn variants were performed using the working parameters presented in table 2.

Table 2. Experiments' parameters

\begin{tabular}{|c|c|c|c|c|}
\hline No. & Working parameters & FPES yarn & MPES yarn & MOPES yarn \\
\hline 1 & Time (hours) & 16.10 & 15.00 & 15.00 \\
\hline 2 & No. of cycles/min & & 600 \\
\hline 3 & No. of cycles/total & 582000 & 540000 & 528000 \\
\hline 4 & Pretention (mg) & \multicolumn{3}{|c|}{40} \\
\hline
\end{tabular}

Morphological characterization of the collected particles was achieved by scanning electron microscopy (SEM), using an FEI Quanta 200 instrument, equipped with an EverhartThornley (ET) detector and using an acceleration voltage of $15 \mathrm{kV}$, in low vacuum mode. Microparticles were taken on the device tablet directly from the collecting Petri dishes (figures 7, 8 and 9).

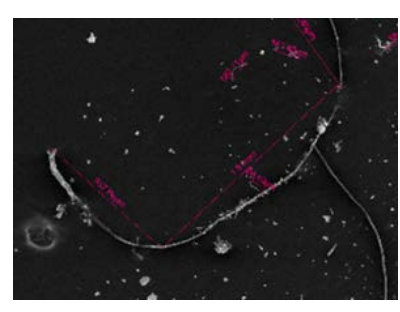

a

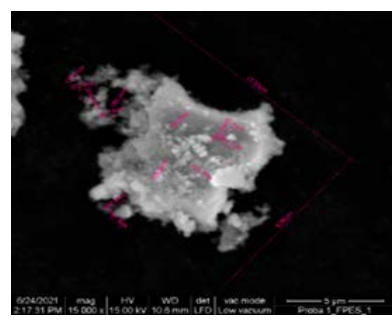

b

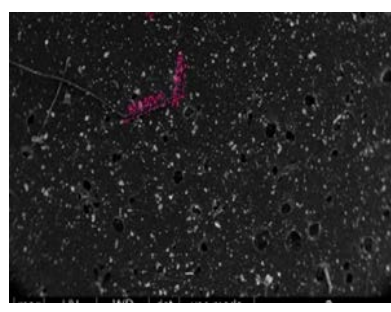

C

Figure 7. SEM images FPES sample: a - microfibrils; b - agglomerations; c - particles 


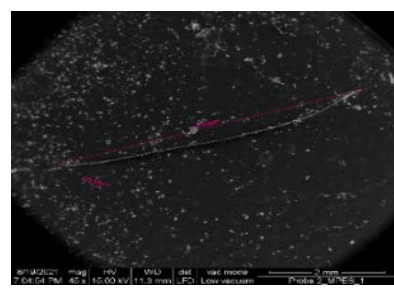

a

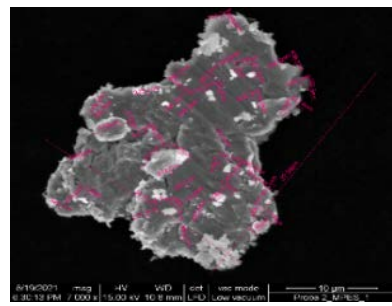

b

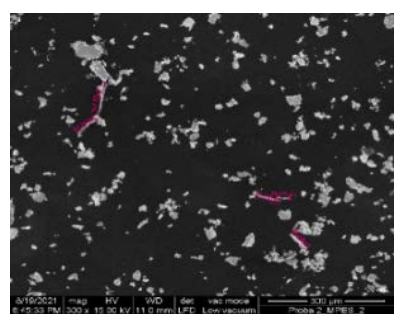

$C$

Figure 8. SEM images MPES sample: a) microfibrils b) agglomerations c) particles

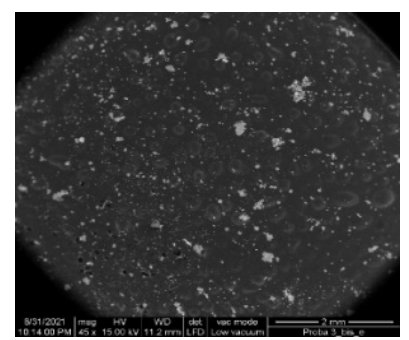

$\boldsymbol{a}$

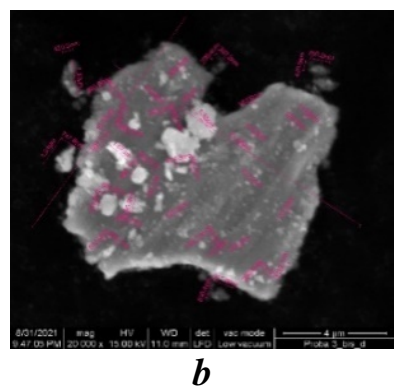

Figure 9. SEM images MOPES sample: a) agglomerations b) particles

In figures 7, 8 and 9 SEM images of airborne particles resulting from the application of the FPES, MPES si MOPES yarns friction test are presented.

The shape and size of particles, agglomerations, and fibrils in $\mu \mathrm{m}$ were determined. The characterization of the 3 statistical populations considered to define the type and size of the collected particles were performed, using specialized software, which allowed the analysis of the obtained data (using the ANALYZE menu) and their visualization (GRAPHS menu).

Variables that entered the analysis: particle area (round, rectangular) in $\mu m^{2}$, the surface of particle agglomerations in $\mu \mathrm{m}^{2}$, and fibril sizes (length) in $\mu \mathrm{m}$.

The scores obtained from the experiments (for each statistical population studied) allowed the calculation of the main parameters of the distributions for each variable. The obtained values and the afferent histograms are presented in table 3 and figure 10.

\section{FPES variant (Figure 10)}

The variables "rectangle FPES1" and "circle FPES1" do not show great variability of the results, the "boxes" having small dimensions. However, for "FPES1 circle", the value no. $12(0.116 \mu \mathrm{m} 2)$ is an extreme case, being located at a distance of more than 3 box lengths.

The variable "FPES1 agglomerations" highlights the distribution of $50 \%$ of the values, the lower edge representing the $25 \%$ percentile value, and the upper one the $75 \%$ percentile value. Thus, it is found that $25 \%$ of the values are below $5.55 \mu \mathrm{m}^{2}, 25 \%$ are between 5.55 - $12.37 \mu \mathrm{m}^{2}$, 25\% between $12.37-127.1 \mu \mathrm{m}^{2}$ and $25 \%$ over $127.1 \mu^{2}$. The value identified by 1 in the database (real value $324.48 \mu \mathrm{m}^{2}$ ) is considered extreme in the range of 1.5 - 3 lengths. Also, the median is directed towards the lower edge of the "box", so it can be stated that the distribution is directed to the left and the small values are predominant (figure 11). 
Table 3. Statistical indicators

\begin{tabular}{|c|c|c|c|c|c|c|c|c|c|c|c|}
\hline \multirow{2}{*}{ Shapes } & \multirow{2}{*}{ Mean } & \multirow{2}{*}{ Median } & \multirow{2}{*}{$\begin{array}{c}\text { Std. } \\
\text { Deviation }\end{array}$} & \multirow{2}{*}{ Variance } & \multirow{2}{*}{ Skewness } & \multirow{2}{*}{ Kurtosis } & \multirow{2}{*}{ Min. } & \multirow{2}{*}{ Max. } & \multicolumn{3}{|c|}{ Percentiles } \\
\hline & & & & & & & & & 25 & 50 & 75 \\
\hline $\begin{array}{l}\text { Rectangular } \\
\text { shape FPES1 }\end{array}$ & 0.79 & 0.37 & 1.42 & 2.04 & 4.64 & 25.38 & 0.04 & 9.23 & 0.18 & 0.37 & 0.74 \\
\hline Circle FPES1 & 0.02 & 0.01 & 0.02 & 0 & 311 & 11 & 0 & 0.11 & 0.01 & 0.01 & 0.02 \\
\hline $\begin{array}{l}\text { Agglomeration } \\
\text { FPES1 }\end{array}$ & 69.51 & 12.37 & 96.6 & 9332.61 & 1.87 & 3.21 & 3.27 & 338.64 & 5.55 & 12.37 & 127.1 \\
\hline \begin{tabular}{|l|} 
Microfibrils \\
FPES1 \\
\end{tabular} & 361.2 & 279.1 & 223.21 & 49826.31 & 0.98 & 0.03 & 109 & 973.17 & 196 & 279.1 & 520.9 \\
\hline $\begin{array}{l}\text { Rectangular } \\
\text { shape } \\
\text { MFILPES2 }\end{array}$ & 1.25 & 0.55 & 1.8 & 3.25 & 2.6 & 6.73 & 0.03 & 8.38 & 0.21 & 0.55 & 1.44 \\
\hline \begin{tabular}{|l} 
Circle \\
MFILPES2
\end{tabular} & 08 & 0.06 & 0.06 & 0 & 1.88 & 27 & 0.01 & 0.33 & 0.03 & 0.06 & 0.11 \\
\hline \begin{tabular}{|l|} 
Agglomeration \\
MFILFPES2
\end{tabular} & 71.92 & 10.24 & 120.79 & 14592.41 & 1.73 & 1.53 & 2.11 & 325.96 & 5.67 & 10.24 & 119.3 \\
\hline \begin{tabular}{|l} 
Microf \\
MFILF
\end{tabular} & 160.9 & 150.28 & 96.92 & 9394.06 & 0.68 & -0.21 & 35.2 & 352 & 65.8 & 150.3 & 229.5 \\
\hline $\begin{array}{l}\text { Rectangular } \\
\text { shape } \\
\text { MOPES3 } \\
\end{array}$ & 0.68 & 0.43 & 0.72 & 0.52 & 1.59 & 2.5 & 0.01 & 3.23 & 0.13 & 0.43 & 0.92 \\
\hline \begin{tabular}{|l} 
Circle \\
MOPES3
\end{tabular} & 0.04 & 0.03 & 0.048 & 0 & 2.71 & 10.27 & 0 & 0.26 & 0.01 & 0.03 & 0.06 \\
\hline \begin{tabular}{|l} 
Agglomeration \\
MOPES3
\end{tabular} & 387.8 & 230.58 & 567.38 & 321924 & 1.63 & 1.33 & 2.8 & 1614 & 6.86 & 230.6 & 317.2 \\
\hline $\begin{array}{l}\text { brils } \\
33\end{array}$ & 68.64 & 87.13 & 59.01 & 3482.22 & -1.27 & - & 2.6 & 116.2 & 2.6 & 87.13 & - \\
\hline
\end{tabular}

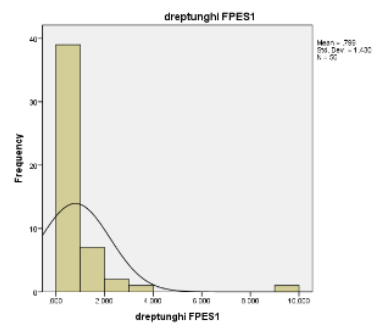

$\boldsymbol{a}$

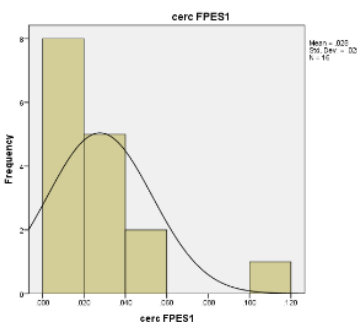

$\boldsymbol{b}$

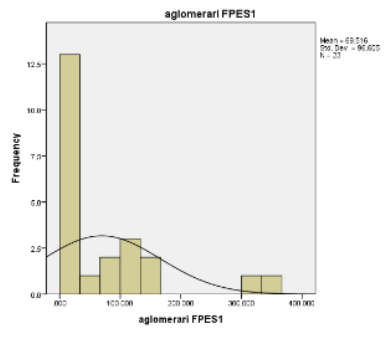

$c$

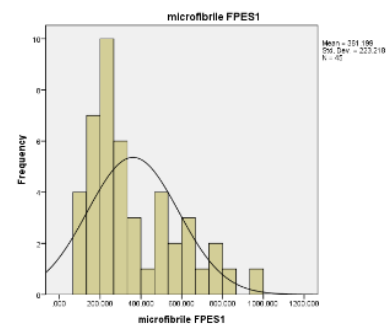

d

Figure 10. Histograms for particle surface variables: $a$ - round; $b$ - rectangular; c - surface of particle agglomerations; d - fibril dimensions (length) - FILPES1

The variable microfibrils FPES1 does not present extreme cases, the median being directed as in the previous case, towards the lower edge of the "box", so the small values being predominant. Additionally, 50\% of the values are in the range [196; 520.9] $\mu^{2}$.

\section{MPES variant}

As in the previous case, the first 2 variables (related to the shape of the identified particles) do not show large variations of the values, but in the case of the variable "rectangle MFILPES2", value no. 6 from the database (real value 8,385 $\mu^{2}$ ) is considered extreme value is located in the range of 1.5 - 3 box lengths. 


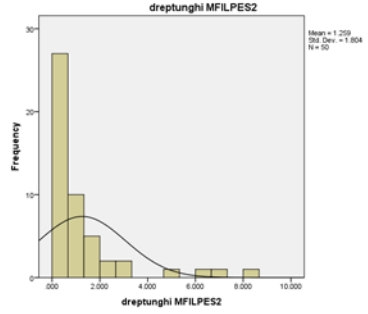

a

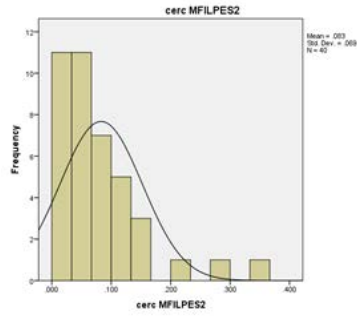

b

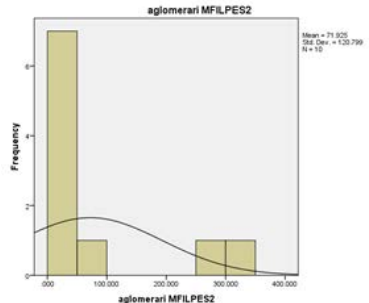

C

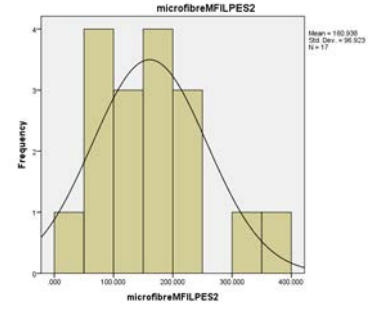

d

Figure 11. Histograms for particle surface variables: $a$ - round; $b$ - rectangular;

c - surface of particle agglomerations; d - fibril dimensions (length) - MFILPES2

The variable “agglomerations MFILPES2" presents the median placed towards the lower edge of the box, so the distribution is directed to the left and the small values are predominant. The outer limits of the graph highlight the small values within 1.5 lengths. The values 5 and 6 in the base, respectively $267.05 \mu \mathrm{m}^{2}$ and $325.96 \mu \mathrm{m}^{2}$ are considered extreme. In this case, there is a large spread of values, $25 \%$ of the values being located below 5.67 $\mu \mathrm{m}^{2}, 50 \%$ are located in the range [5.67; 119.32$] \mu \mathrm{m}^{2}$ and $25 \%$ over $119.32 \mu^{2}$.

The variable "microfibrils MFILPES2" does not present extreme cases, however, there is a very high variability of the data, $50 \%$ of the values being located in the range [65.78; 229.50] $\mu \mathrm{m}^{2}$.

\section{MOPES variant}

There is no large data scattering for the variables "rectangle MOPES3", "circle MOPES3", and "microfiber MOPES3". In the case of this last variable, the median is placed towards the upper edge of the box, so the distribution is inclined to the right, and therefore the large values predominate.

The variable "MOPES3 agglomerations" shows the median placed towards the lower edge of the box (figure 13) so the distribution is directed to the left and the small values are predominant. However, there is a very high variability of the data, with $50 \%$ of the values being in the range $[6.86 ; 317.23] \mu^{2}$.

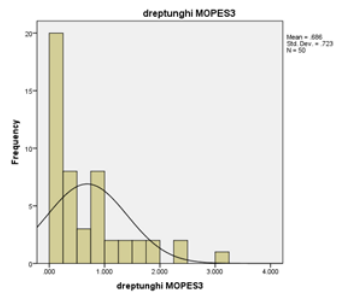

a

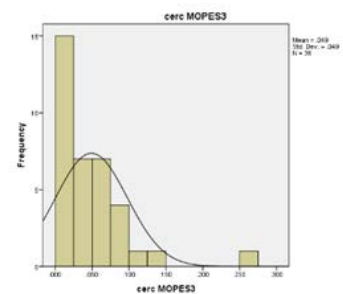

$\boldsymbol{b}$

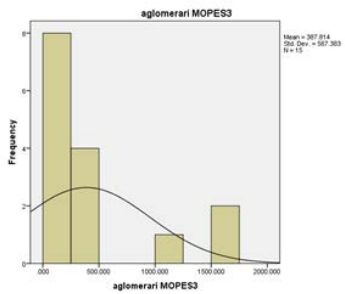

C

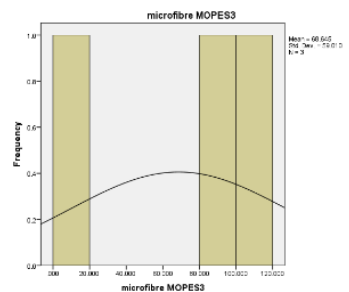

d

Figure 12. Histograms for particle surface variables: $a$ - round; $b$ - rectangular; c - surface of particle agglomerations; d - fibril dimensions (length) - MOPES3

For all variables, the coefficient of variability is higher than $30 \%$, so the arithmetic mean is not representative for any sample, the groups being inhomogeneous.

The skewness index for 8 of the 12 variables does not exceed \pm 1.96 , highlighting, in this case, the extent to which the average moves away from the median and implicitly the curve of normal data distribution moves away from the middle, moving to the left (at FPES1 agglomerations, FPES1 microfibers, MFILPES2 circle, MFILPES2 agglomerations, MFILPES2 microfibers, MOPES3 rectangle, MOPES3 agglomerations) and to the right for MOPES3 microfibers, respectively. For the other 4 variables, it is found to be out of normal. 
The vaulting index (kurtosis) has positive values, so the distribution is leptocortical within the limits of a normal distribution for FPES1 microfibers, MFILPES2 agglomerations, and MOPES3 agglomerations, and MFILPES2 microfiber platicurtica. For the other 8 variables, it is found that the distributions are out of normal.
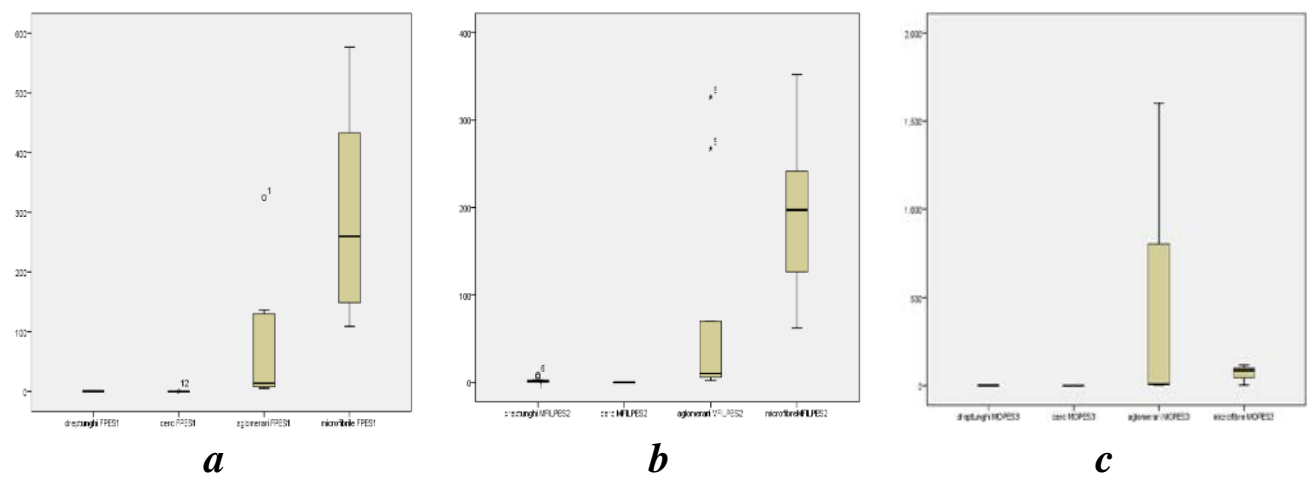

Figure 13. Boxplot graphs for particle surface variables: a - round; b - rectangular; c - the surface of the particle agglomerations; $\mathrm{d}$ - the dimensions of the fibrils (length)

\section{CONCLUSIONS}

Polyester particles were collected in laboratory experiments that simulated the rubbing of threads in the cochleae of weaving machines. The morphological analysis of the particles showed that:

- for variant FPES - 37\% of the identified particles have a parallelepiped shape, 12\% have a spherical shape, $17 \%$ are agglomerations of particles and $34 \%$ are microfibrils;

- for MPES variant - 43\% of the identified particles have a parallelepiped shape, 34\% have a spherical shape, $9 \%$ are agglomerations of particles and $14 \%$ are microfibrils;

- for MOPES variant - $48 \%$ of the identified particles have a parallelepiped shape, $35 \%$ have a spherical shape, $14 \%$ are agglomerations of particles and $3 \%$ are microfibrils.

\section{ACKNOWLEDGEMENTS}

This research is carried out within the project:" Understanding exposure and toxicity of Micro- and Nano-Plastic contaminants in humans, POLYRISK” - Horizon 2020, Call: H2020-SC1-BHC-2018-2020" (Better Health and care, economic growth and sustainable health systems).

\section{REFERENCES}

[1] Galloway, T.S., Micro- and Nano-plastics and Human Health, Bergmann M., Gutow L., Klages M. (eds) Marine Anthropogenic Litter. Springer, Cham., 2015

[2] Marie, E., Cyril, H., Peter, D.H., Veeriah, J., Johannes, V., Damien, L.C., Judy, L., Ludovic, F.D., Nano/micro plastics - Challenges on quantification and remediation: A review, In: Journal of Water Process Engineering, 2021, 42, 102128, ISSN 2214-7144

[3] Manish, K., Hongyu, C., Surendra, S., Shiyi, Q., Huimin, L., Mukesh, K.A., Sunil, K., Lal, S., Zengqiang, Z., Nanthi, S.B., Ashok, P., Sunita, V., Mohammad, J.T., Current research trends on micro- and nano-plastics as an emerging threat to global environment: A review, In: Journal of Hazardous Materials, 2021, 409, 124967, ISSN 0304-3894

[4] Plastics Europe, 2018, Available at: https://www.plasticseurope.org/application/files/6315/4510/ 9658/Plastics_the_facts_2018_AF_web.pdf [Accessed on June 2021] 
[5] Gigault, J., Halle, A., Baudrimont, M., Pascal, P.Y., Gauffre, F., Phi, T.L., El Hadri, H., Grassl, B., Reynaud, S., Current opinion: what is a nanoplastic, In: Environ. Pollut., 2018, 235, 1030-1034

[6] Yee, Maxine S.-L., Hii, L.-W., Looi, C.K., Lim, W.-M., Wong, S.-F., Kok, Y.-Y., Tan, B.-K., Wong, C.-Y., Leong, C.-O., Impact of Microplastics and Nanoplastics on Human Health, Nanomaterials, 2021, 11, 2, 496

[7] Ma, Y.N., Wang, L., Wang, T., Chen, Q.Q., Ji, R., Microplastics as vectors of chemicals and microorganisms in the environment, In: Bolan, N.S., Kirkham, M.B., Halsband, C., Nugegoda, D., Ok, Y.S. (Eds.), Particulate Plastics in Terrestrial and Aquatic Environments, CRC Press, 2020, 209230

[8] Chibuisi, G.A., Caterina, F., Saravanadevi, S., Adebayo, L.O., Kannan, K., Micro(nano)-plastics in the environment and risk of carcinogenesis: Insight into possible mechanisms, In: Journal of Hazardous Materials, 2021, 416, 126143, ISSN 0304-3894

[9] Gopinath, P.M., Saranya, V., Vijayakumar, S., Mythili Meera, M., Ruprekha, S., Kunal, R., Pranay, A., Thomas, J., Mukherjee, A., Chandrasekaran, N., Assessment on interactive prospectives of nanoplastics with plasma proteins and the toxicological impacts of virgin, coronated and environmentally released-nanoplastics, In: Sci. Rep., 2019, 9, 1-15

[10] Marks, R., Robinson, ATC., Woven cloth construction. Manchester: The Textile Institute, 1973 